\title{
An expedient synthesis of some new Pyrazole, Pyrazolone, Hydrazone and
}

\section{Thiosemicarbazide}

\author{
Mohd. Shahnawaz Khan ${ }^{1 *}$, Daya. S. Seth ${ }^{2}$ \\ ${ }^{1}$ Department of Chemistry, JK. Lakshmipat University Jaipur (Raj) -302026, India, \\ ${ }^{2}$ Department of Chemistry, School of Chemical Sciences, St. John's College, Agra (UP)-282002, \\ India
}

*Author for correspondence; E-mail: $\underline{\text { shaanorganic79@gmail.com }}$

\begin{abstract}
:
Malonamic acid, Malonamic acid hydrazide and Malonamic acid amide was designed and synthesized from direct condensation of diethyl malonate with $\mathrm{m}-\mathrm{NO}_{2}$ primary aromatic aniline which used as precursor for synthesis of various possible bio active molecules. We also designed and synthesized the novel non cyclic and heterocyclic compounds from malonamic acid hydrazide like hydrazone, thiosemicarbazide, pyrazole and pyrazolone were achieved by a single step condensation reaction in good to excellent yields. The simple starting materials, mild conditions, easy operation, high bioactivity of hydrazone, thiosemicarbazide, pyrazole and pyrazolone derivatives, this protocol has great potential in medicinal chemistry. All synthesized compounds evaluated for their antimicrobial activity and screening results are awaited. The structure elucidation of synthesized compounds was established on the basis of IR \& NMR techniques ( $\left.{ }^{1} \mathrm{H}-\mathrm{NMR}\right)$ and elemental analysis.
\end{abstract}

Key words: Synthesis; Malonamic Acid Hydrazide; Hydrazone; Thiosemicarbazide; Pyrazole; Pyrazolone;

\section{Introduction:}

Development of drug resistance in microorganism is a scuffle between science and nature. With an increase the antibiotic-resistant strain of microorganism increasing the public health problem [1]. Cyclic and noncyclic compounds containing the reactive methylene group provide magnificent intermediates in synthetic organic chemistry. These molecules have been found to be useful a precursor for various biological active agents. Using such type of compounds as starting material quiet a large number of heterocyclic and non-heterocyclic compounds can be prepared by condensing them with other substances. Heterocycles form by far the largest of classical divisions of organic chemistry. A broad spectrum of biological activity associated with heterocyclic compounds has attracted interest in drug discovery research. Various literature reported that, both synthetic as well as natural nitrogen containing heterocyclic molecules possesses a significant pharmaceutical importance, a large number have been made up to clinics for health care worldwide. Pyrazole and pyrazolone are classes of heterocycles which exhibits diverse chemical and biological properties ${ }^{[2-15]}$. 
Also the non-heterocyclic compounds like hydrazones and thiosemicarbazides have attracted researchers for their significant application in medicinal and agricultural chemistry ${ }^{[16-27]}$.

\section{MATERIALS AND METHODS:}

The purity of the synthesized compounds were checked on silica-gel-coated Al plates (Merck) various solvent systems using iodine vapors as detecting agent. Melting points were determined by the melting point determination apparatus in open capillary tubes and are uncorrected. On the basis of their Infra-red spectra (IR) using KBr discs, on a Perkin Elmer Spectrum RX1 infra-red spectrophotometer. ${ }^{1} \mathrm{H}$ NMR spectra were recorded in DMSO- $\mathrm{d}_{6}$ on Bruker DRX-300 (300 MHz) and Jeol AL300 FT-NMR (300 MHz) systems; chemical shift $(\delta)$ is reported in ppm using TMS as an internal reference. Elemental analysis was performed on Elementor Vario EL III. All the compounds gave satisfactory microanalysis. All chemicals and reagents were obtained from $\mathrm{CDH}$ and Spectrochem Pvt. Ltd. (India) and were used without further purification.

\section{General procedure for the preparation of compounds:}

The title compounds were prepared in following steps:

1. 3-(3-nitrophenylamino)-3-oxopropanoic acid (I): To the 3-nitro aniline (0.05 moles, $6.9 \mathrm{gm})$, diethyl malonate $(0.05 \mathrm{~mol})$ was added and refluxed for $2 \mathrm{hr}$. It was then cooled and filtered. $10 \mathrm{ml}$ ethanol was added to the filtrate and the solution was concentrated on steam bath. Steam was blown into the mixture of above concentrated solution and $20 \mathrm{ml}$ ethanol in the presence of $20 \% \mathrm{Na}_{2} \mathrm{CO}_{3}$ solution $(10 \mathrm{ml})$. It was then cooled and filtered. To the filtrate, conc. $\mathrm{HCl}$ was added. The cream colored solid thus separated was filtered, washed with water and recrystallized from absolute ethanol.

Spectral data for compound (I): Yield: $71.11 \%$; m.p. $120-122^{\circ} \mathrm{C}$; IR( $\left.\mathrm{KBr}, v, \mathrm{~cm}^{-1}\right)$ : 737 (C-H bending), 1351(C- $\mathrm{NO}_{2}$ str.), $1433\left(\mathrm{CH}_{2}\right.$ asmymetric deformation), 1486 (benzene ring str.), 1594 (-CONH- str.), 2729 (O-H str.), 2823 (C-H str. aliphatic), 3355 (N-H str.); ${ }^{1} \mathrm{H}$ NMR (300 MHz, DMSO-d $\left.{ }_{6}\right) \delta: 3.63$ (s, 2H, $\left.\mathrm{CH}_{2}\right), 7.59-7.94$ (m, 4H, Ar$\mathrm{H}), 8.61(\mathrm{~s}, 1 \mathrm{H}, \mathrm{CONH}), 10.66(\mathrm{~s}, 1 \mathrm{H}, \mathrm{COOH})$. Microanalysis: $\mathrm{C}_{9} \mathrm{H}_{8} \mathrm{O}_{5} \mathrm{~N}_{2}$ : calc., \%: $\mathrm{C}$ 48.21, H 3.57, N 12.50; found \%: C 48.30, H 3.55, N 12.53.

2. 3-(3-nitrophenylamino)-3-oxopropanehydrazide (II): To the 3-nitro aniline (0.05 moles, $6.9 \mathrm{gm})$, diethyl malonate $(0.05 \mathrm{~mol})$ was added and refluxed for $2 \mathrm{hr}$. It was then cooled and filtered. $10 \mathrm{ml}$ ethanol was added to the filtrate and the solution was concentrated on the steam bath. After cooling it to the room temperature, $20 \mathrm{ml}$ ethanol and hydrazine hydrate ( 0.05 mole, $99 \%)$ was added and refluxed for 45 mins on the steam bath. On cooling, white crystalline solid was separated; it was then filtered and recrystallized from absolute ethanol.

Spectral and analytical data for compound (II): Yield: $85.96 \%$; m.p 152-154 ${ }^{\circ} \mathrm{C}$. $\operatorname{IR}\left(\mathrm{KBr}, v, \mathrm{~cm}^{-1}\right) 741(\mathrm{C}-\mathrm{H}$ bending), 1012 (C-N str. \& ArC-H bending), 1511 (-N-Nstr.), 1595 (-CONH- str.), 1629 (C=C str.), 2810 (C-H str.), 3478 (N-H str.); ${ }^{1} \mathrm{H}$ NMR (300 MHz, DMSO-d $\left.\mathrm{d}_{6}\right) \delta: 3.54\left(\mathrm{~s}, 2 \mathrm{H}, \mathrm{CH}_{2}\right), 4.30\left(\mathrm{~s}, 2 \mathrm{H}, \mathrm{NH}_{2}\right), 5.79(\mathrm{~s}, 1 \mathrm{H}, \mathrm{CONH}), 7.59-$ 
$8.56(\mathrm{~m}, 4 \mathrm{H}, \mathrm{Ar}-\mathrm{H}), 9.21$ (s, $1 \mathrm{H}, \mathrm{CONH}-\mathrm{Ar})$. Microanalysis: $\mathrm{C}_{9} \mathrm{H}_{10} \mathrm{O}_{4} \mathrm{~N}_{4}$ : calc., \%: C 45.38, H 4.20, N 23.53; found, \%: C 45.40, H 4.18, N 23.55.

3. $\mathbf{N}^{1}$-(3-nitrophenyl)malonamide (III): To the 3-nitro aniline (0.05 moles, $\left.6.9 \mathrm{gm}\right)$, diethyl malonate $(0.05 \mathrm{~mol})$ was added and refluxed for $2 \mathrm{hr}$. It was then cooled and filtered. $10 \mathrm{ml}$ ethanol was added to the filtrate and the solution was concentrated on the steam bath. After cooling, $10 \mathrm{ml}$ ethanol and $10 \mathrm{ml}$ of liquor ammonia $(\mathrm{d}=0.88)$ was added to this concentrated solution, taken in a flask. The flask is tightly corked and shaken vigorously for $1 \mathrm{hr}$. leaving it overnight, pale yellow crystalline solid was separated; it was then filtered and recrystallized from absolute ethanol.

Spectral and analytical data for compound III: Yield: $70.14 \%$; m.p $178-180{ }^{\circ} \mathrm{C}$. IR: $\left(\mathrm{KBr}, v, \mathrm{~cm}^{-1}\right) 1352$ (C-NO 2 str.), 1592 (-CONH- str.), 1630 (C=C str.), 1689 (-CONH str.), 2928 (C-H str.), 3445 (N-H str.); ${ }^{1} \mathrm{H}$ NMR (300 MHz, DMSO-d $\mathrm{d}_{6}$ ) $\delta: 3.59$ (s, 2H, $\left.\mathrm{CH}_{2}\right), 5.79$ (s, $\left.2 \mathrm{H}, \mathrm{NH}_{2}\right), 7.54-7.95(\mathrm{~m}, 4 \mathrm{H}, \mathrm{Ar}-\mathrm{H}), 8.64(\mathrm{~s}, 1 \mathrm{H}, \mathrm{CONH})$,. Microanalysis: $\mathrm{C}_{9} \mathrm{H}_{9} \mathrm{O}_{4} \mathrm{~N}_{3}$ : calc., \%: C 48.43, H 4.04, N 18.83; found, \%: C 48.42, H 4.05, N 18.90.

4. 1-(3-nitro anilino malonyl)-2-(2-imino-3',4'-dimethoxy) phenyl hydrazone (IV): A mixture of compound II (0.001 mole, $0.224 \mathrm{gm}), 3$,4-dimethoxy benzaldehyde $(0.001$ mole, $0.166 \mathrm{gm}$ ) and $20 \mathrm{ml}$ absolute ethanol was refluxed for $3 \mathrm{hr}$. On cooling, the product separated. It was filtered and purified from absolute ethanol in white crystals.

Spectral and analytical data for compound (IV): Yield: $78.38 \%$; m.p. $240{ }^{\circ} \mathrm{C}$. IR: $\left(\mathrm{KBr}, v, \mathrm{~cm}^{-1}\right) 1058$ (C-N str. \& ArC-H bending), 1279 (-N-N- str.), $1339\left(\mathrm{C}-\mathrm{NO}_{2}\right.$ str.), 1515 (-CONH- str.), 1660 ( $\mathrm{C}=\mathrm{N} \& \mathrm{C}=\mathrm{C}$ str.), 1725 (C=O str.), 2819 ( $\left(-\mathrm{OCH}_{3}\right.$ str.), 2945 (C-H str.), 3445 (N-H str.); ${ }^{1} \mathrm{H}$ NMR (300 MHz, DMSO-d ${ }_{6}$ ) $\delta: 3.31$ (s, $\left.2 \mathrm{H}, \mathrm{CH}_{2}\right), 3.57$ (s, $\left.3 \mathrm{H}, \mathrm{OCH}_{3}\right), 3.79\left(\mathrm{~s}, 3 \mathrm{H}, \mathrm{OCH}_{3}\right), 6.88-7.91(\mathrm{~m}, 7 \mathrm{H}, \mathrm{Ar}-\mathrm{H}), 8.62(\mathrm{~s}, 1 \mathrm{H}, \mathrm{CONH}), 8.11$ (s, $1 \mathrm{H}, \mathrm{N}=\mathrm{CH}$ ), 8.59 (s, $1 \mathrm{H}, \mathrm{CONH}$ ). Microanalysis: $\mathrm{C}_{18} \mathrm{H}_{18} \mathrm{O}_{6} \mathrm{~N}_{3}$ : calc., \%: $\mathrm{C} 58.07, \mathrm{H}$ 4.84, N 11.29; found, \%: C 58.07, H 4.85, N 11.30.

5. 1-(3-nitro anilino malonyl)-4-(4'-fluoro phenyl) thiosemicarbazide (V): A mixture of compound II ( 0.001 mole, $0.224 \mathrm{gm})$, 4-fluoro phenyl isothiocyanate ( 0.001 mole, 0.153 $\mathrm{ml}$ ) and $20 \mathrm{ml}$ absolute ethanol was refluxed for $3 \mathrm{hr}$. On cooling, the product separated. It was filtered and purified from absolute ethanol in white crystals.

Spectral and analytical data for compound (V): Yield: $69.23 \%$; m.p $176-178{ }^{\circ} \mathrm{C}$. IR: ( $\left.\mathrm{KBr}, v, \mathrm{~cm}^{-1}\right) 1012$ (C-F str.), 1050 ( C=S str.), 1350 (C-NO 2 str.), 1590 (-CONH- str.), 2810 (C-H str.), 3438 (N-H str.) ; ${ }^{1} \mathrm{H}$ NMR (300 MHz, DMSO-d 6 ) $\delta: 3.45$ (s, 2H, $\mathrm{CH}_{2}$ ), 7.16-7.96 (m, $8 \mathrm{H}, \mathrm{Ar}-\mathrm{H}), 8.66$ (s, $1 \mathrm{H}, \mathrm{CONH})$. Microanalysis: $\mathrm{C}_{16} \mathrm{H}_{14} \mathrm{O}_{4} \mathrm{~N}_{5} \mathrm{FS}$ : calc., \%: C 49.10, H 3.58, N 17.90, S 8.18; found, \%: C 49.15, H 3.60, N 17.93, S 8.17.

6. 1-(3-nitro anilino malonyl)-3,5-dimethyl-4-(4-nitro phenyl azo) pyrazole (VI): A mixture of compound II (0.001 mole, 0.224 gm), 2,3-diketo-3-(4-nitro phenyl azo) pentane ( 0.001 mole, $0.249 \mathrm{gm}), 20 \mathrm{ml}$ absolute ethanol and 2 drops of glacial acetic acid 
was refluxed for $5 \mathrm{hr}$. On cooling, the product separated. It was filtered and purified from absolute ethanol in orange crystals.

Spectral and analytical data for compound (VI): Yield: $78.26 \%$; m.p 214-216 ${ }^{\circ} \mathrm{C}$. IR: $\left(\mathrm{KBr}, v, \mathrm{~cm}^{-1}\right) 1029$ (C-N str. \& ArC-H bending), 1260 (-N-N- str.) , 1335 (C-NO $\mathrm{N}_{2}$ str.), 1519 (-N=N- str.), 1596 (CONH str.) , 1670 (C=O str.), 2827 (C-H str.), 3436 (N-H str.) ; ${ }^{1} \mathrm{H}$ NMR (300 MHz, DMSO-d $\left.{ }_{6}\right) \delta: 2.79$ (s, 3H, $\left.\mathrm{CH}_{3}\right), 2.70\left(\mathrm{~s}, 3 \mathrm{H}, \mathrm{CH}_{3}\right), 3.32$ (s, 2H, $\mathrm{CH}_{2}$ ), 7.71-8.28 (m, 8H, Ar-H), 8.62 (s, $1 \mathrm{H}, \mathrm{CONH}$ ). Microanalysis: $\mathrm{C}_{20} \mathrm{H}_{17} \mathrm{O}_{6} \mathrm{~N}_{7}$ : calc., $\%$ : C 53.21, H 3.77, N 21.73; found, \%: C 53.25, H 3.75, N 21.33.

7. 1-(3-nitro anilino malonyl)-3-methyl-4-(4-chloro phenyl azo) pyrazolin-5-one (VII): A mixture of compound II (0.001 mole, $0.224 \mathrm{gm})$, ethyl-2,3-dioxobutyrate-2-(4-chloro phenyl azo) hydrazone (0.001 mole, $0.269 \mathrm{gm}), 20 \mathrm{ml}$ absolute ethanol and 2 drops of glacial acetic acid was refluxed for $3 \mathrm{hr}$. On cooling, the product separated. It was filtered and purified from absolute ethanol in yellow solid.

Spectral and analytical data for compound (VII): Yield: $73.33 \%$; m.p 186-189 ${ }^{\circ} \mathrm{C}$. IR: $\left(\mathrm{KBr}, v, \mathrm{~cm}^{-1}\right) 810$ (C-Cl str.), 1029 (C-N str. \& ArC-H bending), 1251 (-N-N- str.), 1350 (C-NO 2 str.), 1485 (-N=N- str.), 1593 (-CONH- str.), 1666 (C=O str. ), 2806 (C-H str.), 3423 (N-H str.); ${ }^{1} \mathrm{H}$ NMR (300 MHz, DMSO-d 6 ) $\delta: 1.04$ (s, 3H, $\left.\mathrm{CH}_{3}\right), 2.24$ (s, 1H, $\mathrm{CH}$ pyrazolone ring), 3.37 (s, 2H, $\left.\mathrm{CH}_{2}\right), 7.47-7.92(\mathrm{~m}, 8 \mathrm{H}, \mathrm{Ar}-\mathrm{H}), 8.59$ (s, 1H, CONH). Microanalysis: $\mathrm{C}_{19} \mathrm{H}_{15} \mathrm{O}_{5} \mathrm{~N}_{6} \mathrm{Cl}$ : calc., \%: C 51.53, H 3.39, $\mathrm{N} 18.98$; found, \%: $\mathrm{C} 51.52, \mathrm{H}$ 3.40, N 18.98 .

\section{Result and Discussion:}

To gain access to a good amount of novel malanomic acid (I), hydrazide (II) and amide (III) by direct condensation of commercially available diethyl malonate and 3-nitroaniline in absence of acid or base catalyst. Diethyl malonate and 3-nitro aniline was refluxed in equimolar proportion. It was then cooled and concentrated at room temperature. N-(3-nitro) phenyl malonamic acid(I), $\mathrm{N}$-(3-nitro) phenyl malonamic acid hydrazide (II) and N-(3-nitro) phenyl malonamide (III) were obtained by treating the above concentrated liquid with hydrazine hydrate $(99 \%)$ and ammonia $(\mathrm{d}=0.88)$ respectively. The chemical reaction proceeds as described in Scheme 1. Our next concern was directed towards the reaction of a compound (II). Further, the hydrazide (II) when refluxed with 3,4-dimethoxy benzaldehyde and p-fluoro phenyl isothiocyanate in the presence of ethanol (absolute) furnished hydrazone (IV) and thiosemicarbazide (V) respectively. Pyrazole (VI) and pyrazolin-5-one (VII) is obtained in good yield by condensation of compound (II) with 2,3-diketo-3-(4-nitro phenyl azo)pentane and ethyl-2,3-dioxobutyrate-2-(4-chloro phenyl azo) hydrazone in absolute ethanol with catalytic amount of glacial acetic acid (GAA). Reaction summary is illustrated in Scheme 2. The structures of these compounds were confirmed by analytical and (IR \& ${ }^{1} \mathrm{H}$ NMR) spectral data. The structure of (I) was confirmed by IR spectra which showed the presence of characteristic absorption bands corresponding to (-CONH-) group at $1594 \mathrm{~cm}^{-1},(\mathrm{OH})$ group at $2729 \mathrm{~cm}^{-1},(\mathrm{NH})$ group at $3355 \mathrm{~cm}^{-1} .{ }^{1} \mathrm{H} \mathrm{NMR}$ showed a signal 
corresponding to $\mathrm{CONH}$ group as a singlet at $8.61 \mathrm{ppm}$, signal corresponding to $\mathrm{COOH}$ group as a singlet at $10.66 \mathrm{ppm}$. The structure of compound (II) was confirmed by IR spectra which showed the presence of characteristic absorption bands corresponding to (-CONH-) group at $1595 \mathrm{~cm}^{-1},(-\mathrm{N}-\mathrm{N}-)$ group at $1511 \mathrm{~cm}^{-1},(\mathrm{NH})$ group at $3478 \mathrm{~cm}^{-1} .{ }^{1} \mathrm{H}$ NMR showed a signal corresponding to $\mathrm{CONH}$ group as a singlet at $5.79 \mathrm{ppm}$, signal corresponding to (NH) group as a singlet at 4.30, signal corresponding to $\mathrm{CONH}-\mathrm{Ar}$ group as a singlet at $9.21 \mathrm{ppm}$. The structure of compound (III) give characteristic peaks of various group (CONH) at $1592 \mathrm{~cm}^{-1}$, ( $\mathrm{CONH}_{2}$ str.) $1689 \mathrm{~cm}^{-1}$, (N-H str.) $3445 \mathrm{~cm}^{-1} ;{ }^{1} \mathrm{H}$ NMR showed a signal corresponding to $\mathrm{NH}_{2}$ at $5.79 \mathrm{ppm}$ and for CONH group singlet at $8.64 \mathrm{ppm}$. Compound (IV) was established by their IR spectra showing stretching of various groups at $(\mathrm{C}=\mathrm{O}) 1725,(\mathrm{NH}) 3445,(\mathrm{C}=\mathrm{N} \& \mathrm{C}=\mathrm{C}) 1660$, $\left(\mathrm{OCH}_{3}\right) 2819 \mathrm{~cm}^{-1}$. ${ }^{1} \mathrm{H}$ NMR spectra showing the appearance of two methoxy $\left(\mathrm{OCH}_{3}\right)$ group proton at 3.57-3.79 ppm. The IR spectra of compound (V) displayed new band streching of $(\mathrm{C}=\mathrm{S})$ group at $1050 \mathrm{~cm}^{-1}$ and $(\mathrm{C}-\mathrm{F})$ group at $1012 \mathrm{~cm}^{-1}$. Compounds (VI) and (VII) were established by their IR and ${ }^{1} \mathrm{H}$ NMR spectra both compounds displayed particular new stretching of azo $(-\mathrm{N}=\mathrm{N}-)$ group at $1519-1485 \mathrm{~cm}^{-1}$ and compound give one new band stretching of $(\mathrm{C}-\mathrm{Cl})$ group at $810 \mathrm{~cm}^{-1}$. The proton spectra of compound (VI) showing the two methyl group proton which present on pyrazole ring displayed singlet signal at 2.79-2.70 ppm while compound (VII) showing singlet signal at $1.04 \mathrm{ppm}$ of one methyl group proton and singlet at $2.24 \mathrm{ppm}$ of $\mathrm{CH}$ proton of pyrazolne ring. All synthesized compounds evaluated for their antimicrobial activity and screening results are awaited

\section{Conclusion:}

In our effort to develop novel, versatile and efficient method for the synthesis of bioactive malonamic acid, acid hydrazide, acid amide, hydrazone, thiosemicarbazide, pyrazole and pyrazolone, we herein report efficient synthesis of these candidates from easily commercially available reactive methylene compounds of malonamic acid hydrazide series. Furthermore literature revealed that introduction of methylene $\left(-\mathrm{CH}_{2}-\right)$ group was found to be promising in improving biological profile of compounds. All synthesized compounds evaluated for their antimicrobial activity and results awaited. To the best of our knowledge, the reactions occurred very fast under mild conditions using reasonable reagents and solvents and products yields are also remarkable.

\section{Acknowledgement:}

We are thankful to Central Drug Research Institute (CDRI), Lucknow for spectral and microanalysis. We are grateful to Microbiology Department, G.R. Medical College, Gwalior for providing biological screenings. 


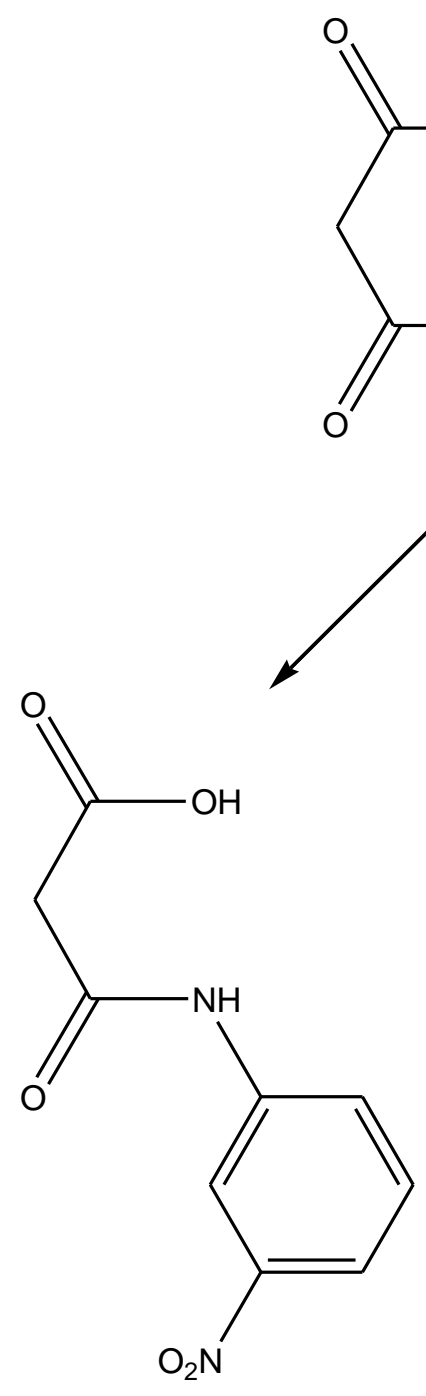

(I)

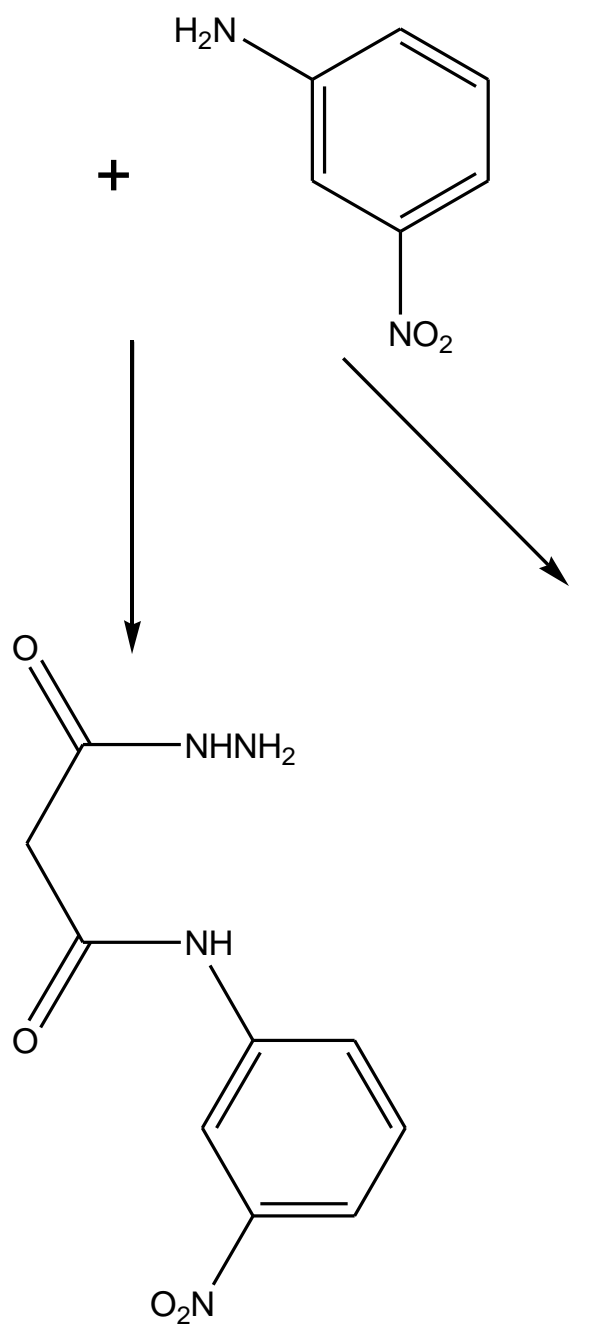

(II)

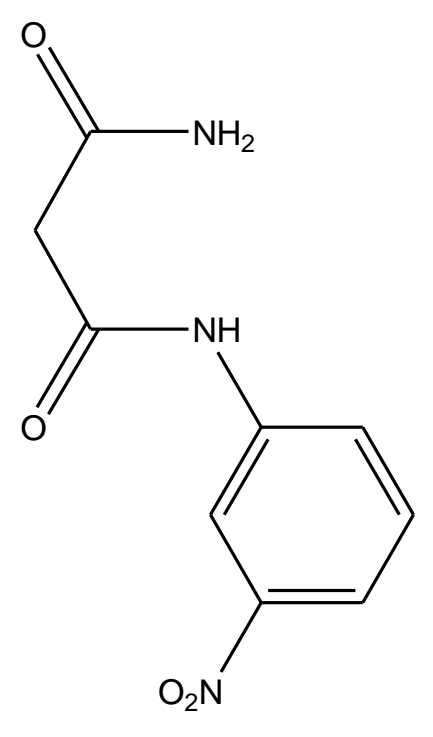

(III)

SCHEME-1 


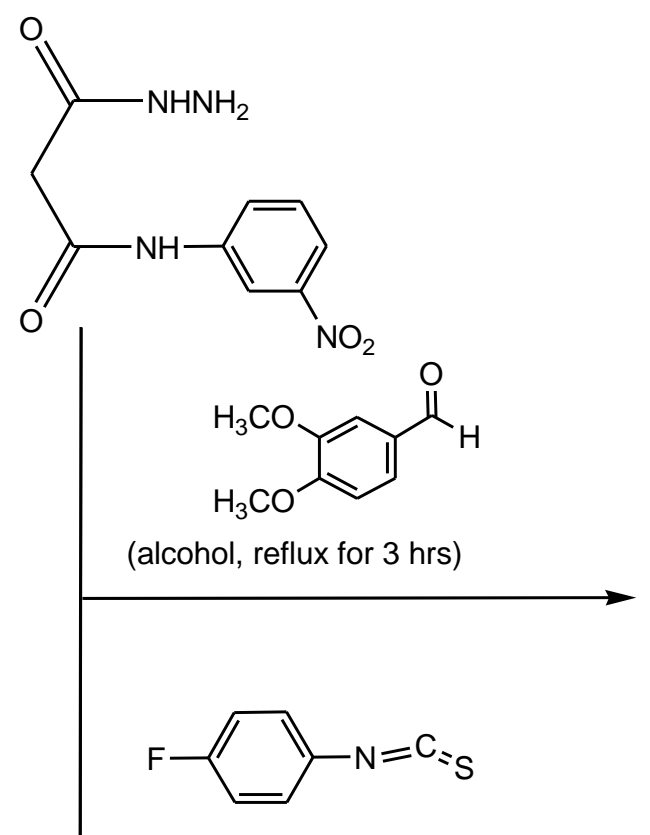

(alcohol, reflux for $3 \mathrm{hrs}$ )

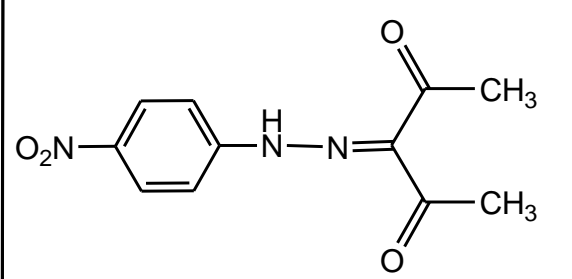

( 2 drops of glacial acetic acid, reflux for $5 \mathrm{hrs}$ )

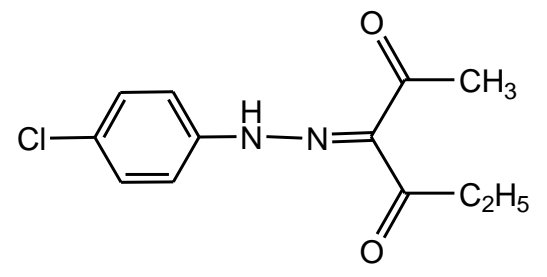

( 2 drops of glacial acetic acid, reflux for $3 \mathrm{hrs}$ )<smiles>COc1ccc(/C=N/NC(=O)CC(=O)Nc2cccc([N+](=O)[O-])c2)cc1OC</smiles>

[1-(3-nitro anilino malonyl)-2-(2-imino-3',4'-dimethoxy) phenyl hydrazone]<smiles>O=C(CC(=O)Nc1cccc([N+](=O)[O-])c1)NNC(=S)Nc1ccc(F)cc1</smiles>

[1-(3-nitro anilino malonyl)-4-(4'-fluoro phenyl) thiosemicarbazide]<smiles>Cc1nn(C(=O)CC(=O)Nc2cccc([N+](=O)[O-])c2)c(C)c1N=Nc1ccc([N+](=O)[O-])cc1</smiles>

[1-(3-nitro anilino malonyl)-3,5-dimethyl-4-(4-nitro phenyl azo) Pyrazole]

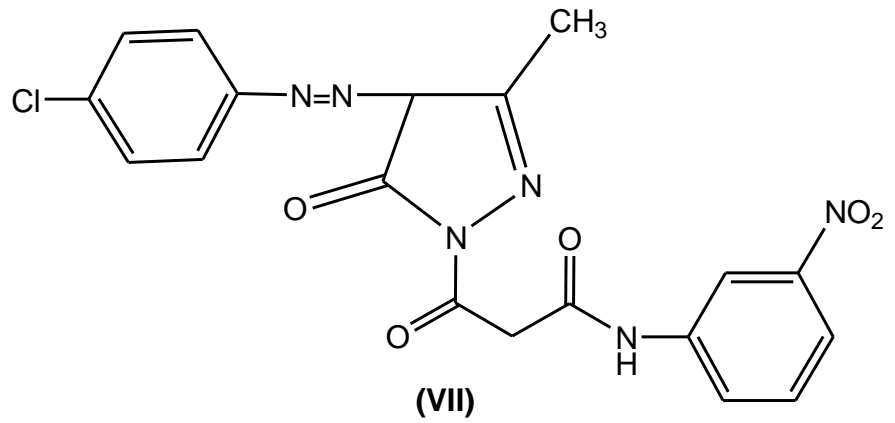

(VII)

[1-(3-nitro anilino malonyl)-3-methyl-4-(4-chloro phenyl azo) pyrazolin-5-one]

SCHEME- 2 
$\underline{\text { Table-1 Physical and analytical data of synthesized compounds }}$

\begin{tabular}{|c|c|c|c|c|c|c|c|c|c|c|}
\hline S. & Compd & M.P & $\%$ & Mol. & \multicolumn{2}{|c|}{ \% Carbon } & \multicolumn{2}{|c|}{ \% Hydrogen } & \multicolumn{2}{|c|}{ \% Nitrogen } \\
\hline & & & & & Found & Calc. & Found & Calc. & Found & Calc. \\
\hline 1 & (I) & $\begin{array}{r}120 \\
-122 \\
\end{array}$ & 71.11 & $\mathrm{C}_{9} \mathrm{H}_{8} \mathrm{O}_{5} \mathrm{~N}_{2}$ & 48.30 & 48.21 & 3.55 & 3.57 & 12.53 & 12.50 \\
\hline 2 & (II) & $\begin{array}{c}152 \\
-154\end{array}$ & 85.96 & $\mathrm{C}_{9} \mathrm{H}_{10} \mathrm{O}_{4} \mathrm{~N}_{4}$ & 45.40 & 45.38 & 4.18 & 4.20 & 23.55 & 23.53 \\
\hline 3 & (III) & $\begin{array}{c}178 \\
-180\end{array}$ & 70.14 & $\mathrm{C}_{9} \mathrm{H}_{9} \mathrm{O}_{4} \mathrm{~N}_{3}$ & 48.42 & 48.43 & 4.05 & 4.04 & 18.90 & 18.83 \\
\hline 4 & (IV) & 240 & 78.38 & $\mathrm{C}_{18} \mathrm{H}_{18} \mathrm{O}_{6} \mathrm{~N}_{3}$ & 58.07 & 58.07 & 4.85 & 4.84 & 11.30 & 11.29 \\
\hline 5 & (V) & $\begin{array}{c}176- \\
178\end{array}$ & 69.23 & $\begin{array}{c}\mathrm{C}_{16} \mathrm{H}_{14} \mathrm{O}_{4} \mathrm{~N}_{5} \\
F S\end{array}$ & 49.15 & 49.10 & 3.60 & 3.58 & 17.93 & 17.90 \\
\hline 6 & (VI) & $\begin{array}{l}214- \\
216\end{array}$ & 78.26 & $\mathrm{C}_{20} \mathrm{H}_{17} \mathrm{O}_{6} \mathrm{~N}_{7}$ & 53.25 & 53.21 & 3.75 & 3.77 & 21.33 & 21.73 \\
\hline 7 & (VII) & $\begin{array}{l}186- \\
189\end{array}$ & 73.33 & $\begin{array}{c}\mathrm{C}_{19} \mathrm{H}_{15} \mathrm{O}_{5} \mathrm{~N}_{6} \\
\mathrm{Cl}\end{array}$ & 51.52 & 51.53 & 3.40 & 3.39 & 18.98 & 18.98 \\
\hline
\end{tabular}

\section{References:}

1. Rice LB. Unmet medicinal needs in antibacterial therapy. Biochem Pharmacol 2006; 71: 991-5

2. Czerney, P, Hartmann H. J. Liebscher, Z. Chem. 1981; 153; 122 (Chem. Abstr. 1982, 97, 57).Kaidbey, H.K, Kligman M. A, Arch. Dermatol. 1981; 117: 258 (Chem. Abstr. 1981, 95, 19141e).

3. Sharshira E. M, Mahrous Hamada N.M. Synthesis and Antimicrobial Evaluation of Some Pyrazole Derivatives Molecules 2012; 17: 4962-71

4. Kidwai M, Singhal K, Rastogi S, Paal knorr reaction for novel pyrrolo [2,3-d] pyrimidines, J. Heterocyclic Chem. 2006; 43: 1231-6

5. Khloya P, Kumar P, Mittal A, Aggarwal N. K, Sharma P. K. Synthesis of some novel 4arylidene pyrazoles as potential antimicrobial agents. Organic and Medicinal Chemistry Letters2013; 3: 9. 
6. Tanitame A, IwaiN, Hiyama Y, Oyamada Y, Nagai K. Synthesis and antibacterial activity of a novel series of DNA gyrase inhibitors;5-[(E)-2-arylvinyl]pyrazoles. J. Med. Chem., 2004; 47(3): 3693-3703.

7. Gautam V, Chawla V, Sonar P, Saraf K. Synthesis, characterization and antimicrobial evaluation of some 1,3,5-trisubstituted pyrazole derivatives. Eur. J. Chem., 2010; 7(3): 1190-1195.

8. Shah P. J. Synthesis and Biological Activities of Novel Arylazopyrazolones Substituted with Thiazolyhydrazone. Journal of the Korean Chemical Society.2014; 58(1): 57-61

9. Yusuf M, Jain P. Synthetic and biological studies of pyrazolines and related heterocyclic compounds. Arabian Journal of Chemistry.2014; 7(5): 553-596

10. Kong Y, Tang M, Wang Y. Regioselective Synthesis of 1,3,5-Trisubstituted Pyrazoles from N-Alkylated Tosylhydrazones and Terminal Alkynes. Org. Lett., 2014; 16 (2): 576579

11. Amir, M.; Kumar, S. Synthesis and anti-inflammatory, analgesic, ulcerogenic and lipid peroxidation activities of 3,5-dimethyl pyrazoles, 3-methyl pyrazol-5-ones and 3,5disubstituted pyrazolines Ind. J. Chem. 2005; 44B: 2532-37.

12. Amir M, Javed S. A, Hassan M. Z. Synthesis and antimicrobial activity of pyrazolinone and pyrazole analogues containing quinoline moiety. Ind. J. Chem. 2013; 52B:1493-1499

13. El-Sayed A. A, Khalil A. M, El-Shahat M, Khaireldin N. Y, Rabie S. T. Antimicrobial activity of PVC-pyrazolone-silver nanocomposites. Journal of Macromolecular Science, Part A. 2016; 53(6): 346-353

14. Karthikeyan M. S, Holla B. S, Kumari N. S. Synthesis and antimicrobial studies on novel chloro-fluorine containing hydroxyl pyrazolines. Eur. J Med. Chem 2007; 42: 30-36.

15. Amir M, Kumar H, Khan SA. Synthesis and pharmacological evaluation of pyrazoline derivatives as new anti-inflammatory and analgesic agents. Bioorg Med Chem Lett 2008; 18: 918-922.

16. Fox H. H, Synthetic tuberculostats. iii. isonicotinaldehyde thiosemicarbazone and some related compounds. J. Org. Chem. 1952; 17(4): 555-62.

17. Patel S R, Gangwal R, Sangamwar A T, Jain R.Synthesis, biological evaluation and 3DQSAR study of hydrazide, semicarbazide and thiosemicarbazide derivatives of 4(adamantan-1-yl)quinoline as anti-tuberculosis agents. Eur J Med Chem. 2014; 6, 85: 255-67. 
18. Altıntop M D, Atlı Ö, Ilgın S, Demirel R, Özdemir A, Kaplancıklı Z A. Synthesis and biological evaluation of new naphthalene substituted thiosemicarbazone derivatives as potent antifungal and anticancer agents. Eur J Med Chem. 2016; 27, 108: 406-14.

19. Abu Khalaf R, Abdula A.M, Mubarak M. S. et al. Tryptophan and thiosemicarbazide derivatives: design, synthesis, and biological evaluation as potential $\beta$-d-galactosidase and $\beta$-d-glucosidase inhibitors. Med Chem Res 2015; 24(6): 2529-50

20. Zong G, Zhao H, Jiang R, Zhang J, Liang X, Li B, Shi Y, Wang D. Design, Synthesis and Bioactivity of Novel Glycosylthiadiazole Derivatives. Molecules 2014; 19: $7832-49$

21. Sharma R, Nagda D P, Talesara G L. Synthesis of various isoniazidoth iazolidinones and their imidoxy derivatives of potential biological interest. ARKIVOC 2006; (i): 1-12

22. Aggarwal N, Kumar R, Srivastva C, Dureja P, Khurana M. Synthesis of Nalidixic acid based hydrazones as novel pesticides. J. Agric. Food Chem. 2010; 58, 3056-61

23. Wang H, Ren Shuang-Xi, He Ze-Yu, Wang De-Long, Yan Xiao-Nan, Feng Jun-Tao, Zhang Xing. Synthesis, Antifungal Activities and Qualitative Structure Activity Relationship of Carabrone Hydrazone Derivatives as Potential Antifungal Agents Int. J. Mol. Sci. 2014; 15: 4257-72.

24. Silva, A.G.; Zapata-Suto, G.; Kummerle, A.E.; Fraga, C.A.M.; Barreiro, E.J.; Sudo, R.T. Synthesis and vasodilatory activity of new $\mathrm{N}$-acylhydrazone derivatives, designed as LASSBio-294 analogues. Bioorg. Med. Chem. 2005; 13: 3431-7.

25. Milan C, Mladen T, Frane C, Elizabeta Has-Schon. Synthesis and Antimicrobial Activity of Some Derivatives on the Basis (7-hydroxy-2-oxo-2H-chromen-4-yl)-acetic Acid Hydrazide. Molecules 2006; 11(2): 134-147.

26. Sevim, R, Kucukguzel, S. G. Biological Activities of Hydrazone Derivatives. Molecules 2007; 12: 1910-39.

27. Patole J, Sandbhor U, Padhye S, Deobagkar D. N, Anson C. E, Powell A. Structural chemistry and in vitro antitubercular activity of acetylpyridine benzoyl hydrazone and its copper complex against Mycobacterium smegmatis. Bioorg. Med. Chem. Lett. 2003;13, $51-55$.

28. Gopalakrishnan M, Thanusu J, Kanagarajan V, Govindaraju R. Design, syntheis and in vitro microbiological evaluation of 6,6-dimethyl-7,9-diaryl-1,2,4,5tetraazaspiro[4,5]decan-3-thiones- A new series of tailor made compounds. J. Enzyme Inhib. Med. Chem. 2009; 24: 406-12. 